\title{
Epibatidine: A Promising Natural Alkaloid in Health
}

\author{
Bahare Salehi ${ }^{1}{ }^{\oplus}$, Simona Sestito ${ }^{2}$, Simona Rapposelli ${ }^{2,3}$, Gregorio Peron ${ }^{4}{ }^{\oplus}$,

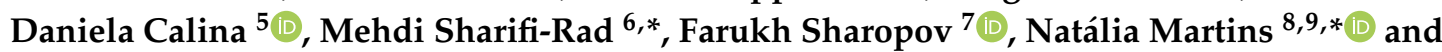 \\ Javad Sharifi-Rad ${ }^{10,11, *(1)}$
}

1 Student Research Committee, School of Medicine, Bam University of Medical Sciences, Bam 44340847, Iran; bahar.salehi007@gmail.com

2 Department of Pharmacy, University of Pisa, Via Bonanno 6, 56126 Pisa, Italy; simona.sestito@for.unipi.it (S.S.); simona.rapposelli@unipi.it (S.R.)

3 Interdepartmental Research Centre for Biology and Pathology of Aging, University of Pisa, 55126 Pisa, Italy

4 Department of Pharmaceutical and Pharmacological Sciences, University of Padova, Via Francesco Marzolo, 5, 35131 Padova (PD), Italy; gregorio.peron@ub.edu

5 Department of Clinical Pharmacy, University of Medicine and Pharmacy Craiova, Craiova 200349, Romania; calinadaniela@gmail.com

6 Department of Medical Parasitology, Zabol University of Medical Sciences, Zabol 61663-335, Iran

7 Department of Pharmaceutical Technology, Avicenna Tajik State Medical University, Rudaki 139, Dushanbe 734003, Tajikistan; shfarukh@mail.ru

8 Faculty of Medicine, University of Porto, Alameda Prof. Hernâni Monteiro, 4200-319 Porto, Portugal

9 Institute for Research and Innovation in Health (i3S), University of Porto, 4200-135 Porto, Portugal

10 Zabol Medicinal Plants Research Center, Zabol University of Medical Sciences, Zabol 61615-585, Iran

11 Department of Chemistry, Richardson College for the Environmental Science Complex, The University of Winnipeg, Winnipeg, MB R3B 2G3, Canada

* Correspondence: mehdi_sharifirad@yahoo.com (M.S.-R.); ncmartins@med.up.pt (N.M.); javad.sharifirad@gmail.com (J.S.-R.); Tel.: +98-54-322-51-790 (M.S.-R.); +351-22-5512100 (N.M.); +98-21-88200104 (J.S.-R.)

Received: 20 November 2018; Accepted: 17 December 2018; Published: 23 December 2018

\begin{abstract}
Epibatidine is a natural alkaloid that acts at nicotinic acetylcholine receptors (nAChRs). The present review aims to carefully discuss the affinity of epibatidine and its synthetic derivatives, analogues to nAChRs for $\alpha 4 \beta 2$ subtype, pharmacokinetic parameters, and its role in health. Published literature shows a low affinity and lack of binding of epibatidine and its synthetic analogues to plasma proteins, indicating their availability for metabolism. Because of its high toxicity, the therapeutic use of epibatidine is hampered. However, new synthetic analogs endowed from this molecule have been developed, with a better therapeutic window and improved selectivity. All these aspects are also discussed here. On the other hand, many reports are devoted to structure-activity relationships to obtain optically active epibatidine and its analogues, and to access its pharmacological effects. Although pharmacological results are obtained from experimental studies and only a few clinical trials, new perspectives are open for the discovery of new drug therapies.
\end{abstract}

Keywords: epibatidine; nicotinic acetylcholine receptors; analgesics; ABT-594; ABT-418

\section{Introduction}

Epibatidine (exo-2-(6-chloro-3-pyridyl)-7-azabicyclo-[2.2.1]heptane) is a toxic alkaloid isolated and identified from Epipedobates tricolor skin, an Ecuadorian poison frog used by indigenous tribes in darts for hunting [1]. Although it was discovered in 1974 by Daly and Myers, epibatidine formula $\mathrm{C}_{11} \mathrm{H}_{13} \mathrm{~N}_{2} \mathrm{Cl}$ and its chemical structure was only established in 1992 using nuclear magnetic resonance spectroscopy [2]. 
This alkaloid is widely considered an analgesic agent, with a potency ranging from 100- to 200-fold higher than the analgesic opioid morphine and 30 times higher than nicotine. The analgesic mode of action of epibatidine is attributed to its interaction with nicotinic acetylcholine receptors (nAChRs), and not with the opioid receptors. Nicotinic acetylcholine receptors are transmembrane oligomeric ligand-gated ion channels and are expressed both central and peripherally. The muscle nAChRs is a pentamer and it consist of a combination of four classes subunits (subunit $\alpha$ expressed in two copies and the other three subunits $\beta, \gamma, \delta$ as single copies) that form a transmembrane aqueous pore. The neuronal nAChRs are pentameric structures with a combination of only two classes of subunits ( $\alpha$ and $\beta$ ). The most abundant heteromeric nAChRs subtypes in the brain are composed of two $\alpha$ and three $\beta$ subunits (i.e., $\left.(\alpha 4)_{2}(\beta 2)_{3}\right)$ [3]. Particularly, in mammalian central nervous system (CNS) the heterodimeric nAChR subtypes $\alpha 4 \beta 2$, and the monomeric subtypes $\alpha 7$ are the most expressed. Epibatidine has high affinity to $\mathrm{nAChRs}$ for the $\alpha 4 \beta 2$ subtype, being a potent, but non-selective ( $\alpha 4 \beta 2$ $\left.K_{\mathrm{i}}=40 \mathrm{pM} ; \alpha 7 K_{\mathrm{i}}=20 \mathrm{nM}\right) \mathrm{nAChR}$ agonist. The inhibitory constant $\left(K_{\mathrm{i}}\right)$ of a drug is known to cause the inhibition of a cytochrome P450 enzyme and have to do with the concentration needed to reduce the activity of that enzyme by half. The $K_{i}$ is reflective of the binding affinity for a drug [4].

Unfortunately, its broad-spectrum of activity induces several off-targets effects in several districts, such as in CNS as well as in respiratory, gastrointestinal, and cardiovascular functions, precluding any therapeutic development [5]. Thus, epibatidine toxicity could be related to its ability to activate not only the central neuronal $\alpha 2 \beta 2$, but also the ganglionic $\alpha 3 \beta 4 \mathrm{nAchR}$.

The great interest in epibatidine arises with the discovery of the analgesic activity mediated by non-opioid receptors. This mode of action is a good alternative to induce analgesia with no risk of dependence, tolerance and psychological dependence. The lack of opioid-receptors mediated activity has been proved by the co-administration of naloxone, an opioid antagonist. The experiment performed by Qian et al. [6] proved that the epibatidine-induced anti-nociception in mice and rats, is not influenced by naloxone, but the effective therapeutic dose is close to the lethal dose and, thus, the therapeutic safety interval is narrow. The main clinical signs of epibatidine toxicity includes activation of exocrine secretions (rhinorrhea, sialorrhea, lacrimation), seizures, hypertension, and muscle paralysis. These effects occur because epibatidine binds to nAChRs in the CNS, as well as to $\mathrm{nAChRs}$ in skeletal neuro-muscular junctions [7]. For instance, Thompson et al. [8] demonstrated that epibatidine binds to $\alpha-7$ nicotinic receptors $(\alpha 7 \mathrm{nACh})$ present both peripherally and centrally in the nervous system. These central receptors are involved in various neurological conditions, such as schizophrenia, Parkinson's, and Alzheimer's disease (AD), but also in other important physiological functions, including neuroprotection, memory and learning, and pain control [9]. For this reason, new ligands of these receptors have been investigated as upcoming pharmacological research tools or as possible drugs.

In light of these aspects, it has been found that the new neuronal nAChRs agonists synthesized have a greater affinity to the $\alpha 4 \beta 2$ receptor subtype of the CNS and low affinity to neuromuscular junction nAChRs. Thus, Abbott Laboratories synthesized a neuronal nACh receptor agonist named ABT-594 (tebanicline or ebanicline) derived from the epibatidine structure, which binds preferentially to $\alpha 4 \beta 2$ receptor subtype [10]. More recently, other studies demonstrated other pharmacological effects of epibatidine. For instance, Shimizu et al. [11] reported increases in adrenaline and noradrenaline concentrations after intracerebroventricular injection of medium doses of epibatidine in rats. Moreover, it has been shown that nicotinic receptors $\alpha 4 \beta 2$ activation in brain produce elevated secretion of catecholamines from adrenal glands [11]. Unexpected outcomes were obtained by Green et al. [12] in recent research. They demonstrated, in an in vivo study using a pregnant goats model, that epibatidine dosed at $0.002 \mathrm{mg} / \mathrm{kg}$ did not completely inhibit fetal movements, but produced intoxication with clinical signs (salivation, muscle fasciculation, urination). These results are important because the complete inhibition of fetal movements is associated with an increased risk of teratogenicity [12]. 


\section{Pharmacokinetics of Epibatidine and Its Synthetic Derivatives}

Epibatidine biological targets and mechanisms of action are now well established [13], but little is known on its pharmacokinetics. Although some parameters, like intestinal absorption, distribution through the blood-brain barrier (BBB) and metabolism by the cytochrome CYP450 enzyme family, can be predicted by means of informatic tools (http://lmmd.ecust.edu.cn/admetsar1) (data about epibatidine can be found on DrugBank (DB07720 at www.drugback.ca)), experimental in vitro and in vivo data still remain scarce. London et al. [14] reported that epibatidine reaches the highest distribution in thalamus and upper colliculus in the brain $30 \mathrm{~min}$ after tail-vein administration in rats. A slow clearance was also observed, with epibatidine still present in brain $4 \mathrm{~h}$ post administration [14]. More recently, Javors et al. [15] investigated epibatidine absorption and distribution using a mouse model. A dose of $0.1 \mathrm{mg} / \mathrm{kg}$ epibatidine was administered intraperitoneally to C57BL/10J mice and the alkaloid concentration was monitored in plasma samples collected $10 \mathrm{~min}$ post-injection [15]. Significantly different amounts of epibatidine were observed between male and female mice, with concentrations of $7.3 \mathrm{ng} / \mathrm{mL}$ for males and $37.1 \mathrm{ng} / \mathrm{mL}$ for females [15]. However, this discrepancy was not discussed further. Similar results were then obtained by Shiraishi and coauthors [16] using a rat model, where a plasma concentration of $5.8 \mathrm{ng} / \mathrm{mL}$ was detected following intraperitoneal injection of $10 \mu \mathrm{g} / \mathrm{kg}$ epibatidine [16].

Data on epibatidine metabolism are scarce. Preliminary observations were published in 2000 by Watt et al. [17]. This research investigated in vitro the route of metabolism of epibatidine $(+)$ and $(-)$ enantiomers. The results showed the formation of the diastereoisomeric N-oxides for $(+)$ for $(+)$ epibatidine and hydroxylation of the azabicycle for (-) epibatidine [17].

Studies on epibatidine metabolism and metabolites excretion have undergone gradual decreased in number due to its severe side effects. More recently, efforts have been made to address the pharmacokinetics of new derivatives of epibatidine with reduced toxicity, as reported by Heugebaert et al. [18]. The authors presented five epibatidine analogs containing a substituent on the azabicyclo[2.2.1] heptane bridgehead, namely a ketone linker, an $\mathrm{OH}$ linker, an aminomethyl linker, and two ethyl linkers containing an $\mathrm{OH}$ and a $\mathrm{NH}_{2}$ group, respectively. Only ketone-binding epibatidine maintained chlorine in the aromatic ring. However, the authors focused their attention only on an aminomethyl- and two ethyl linkers containing an $\mathrm{OH}$ and a $\mathrm{NH}_{2}$ group, due to their higher affinity for $\alpha 4 \beta 2 \mathrm{nAChR}$ [18], and for them studied the in vitro pharmacokinetics. Both compounds showed a low binding affinity to plasma proteins, meaning that they are available for metabolism [18]. Using isolated rat hepatocytes, an evaluation of metabolic stability was carried out and the results indicated compounds with an $\mathrm{OH}$ linker as metabolically stable, while the metabolism of an aminomethyl linker seemed to be concentration-dependent and faster than that of control (verapamil), thus hampering its $\mathrm{t}_{1 / 2}\left(<2 \mathrm{~min}\right.$, compared to $\mathrm{t}_{1 / 2}=175 \mathrm{~min}$ for $\mathrm{OH}$ binding compound; the half-time $\left(\mathrm{t}_{1 / 2}\right)$ is a pharmacokinetic parameter, being defined as the required time to decrease half of the concentration of an active substance in plasma) [18].

Other epibatidine derivatives have been synthetized over the past few years and evaluated for a possible use as radioligands for neuroimaging by positron emission tomography (PET) of $\alpha 4 \beta 2$ nAChR. Among others, radiolabeled derivatives of flubatine (Figure 1), (+)- and $(-)-\left[{ }^{18} \mathrm{~F}\right]$ enantiomers of flubatine seem to represent the most suitable candidates and have been examined in several studies to investigate their metabolic fate both in vitro and in vivo. In a study by Patt et al. [19], plasma protein binding, metabolism, and activity distribution between plasma and whole blood of (-)- enantiomer of $\left[{ }^{18} \mathrm{~F}\right]$ flubatine were investigated in $21 \mathrm{AD}$ patients and 20 healthy controls. The obtained results showed that the amount of $(-)$ - enantiomer of $\left[{ }^{18} \mathrm{~F}\right]$ flubatine that bonded to plasma proteins was $15 \%$, and was found to be poorly metabolized, with almost $90 \%$ of the administered dose remaining unchanged after $90 \mathrm{~min}$ post-injection. In addition, radioactivity distribution between plasma and whole blood only slightly changed over time, from 0.82 at $3 \mathrm{~min}$ post-injection to 0.87 at $270 \mathrm{~min}$ post-injection, indicating the contribution of only a small amount of metabolites [19]. In a more recent study by Ludwig and coauthors [20], the metabolic fate of $(+)$ - enantiomer of $\left[{ }^{18} \mathrm{~F}\right]$ flubatine was 
investigated in a clinical study involving patients with early AD. The same experiment was carried out for non-radiolabeled (+)- enantiomer of flubatine in pigs. For the latter, the six major metabolites detected in urine were formed by monohydroxylation at different sites of the azabicyclic ring system. An intermediate metabolite underwent glucuronidation, both in vitro and in vivo, and was detected in both plasma and urine [20]. In humans, it was observed that $30 \mathrm{~min}$ post-injection, $95.9 \%$ of the administered (+)- enantiomer of $\left[{ }^{18} \mathrm{~F}\right]$ flubatine dose was present in plasma as unmodified, while $95.1 \%$ were present in urine, as further proof of the metabolism stability of these derivatives. As observed in pigs for (+)- enantiomer of flubatine, the main metabolites detected in plasma and urine were formed by monohydroxylation at the azabicyclic ring system $(0.0-3.8 \%$ in plasma and $0.0-4.9 \%$ in urine, $30 \mathrm{~min}$ post-injection) and glucuronidation $(0.0-4.0 \%$ in plasma and $0.4-10.7 \%$ in urine, $30 \mathrm{~min}$ post-injection) [20].

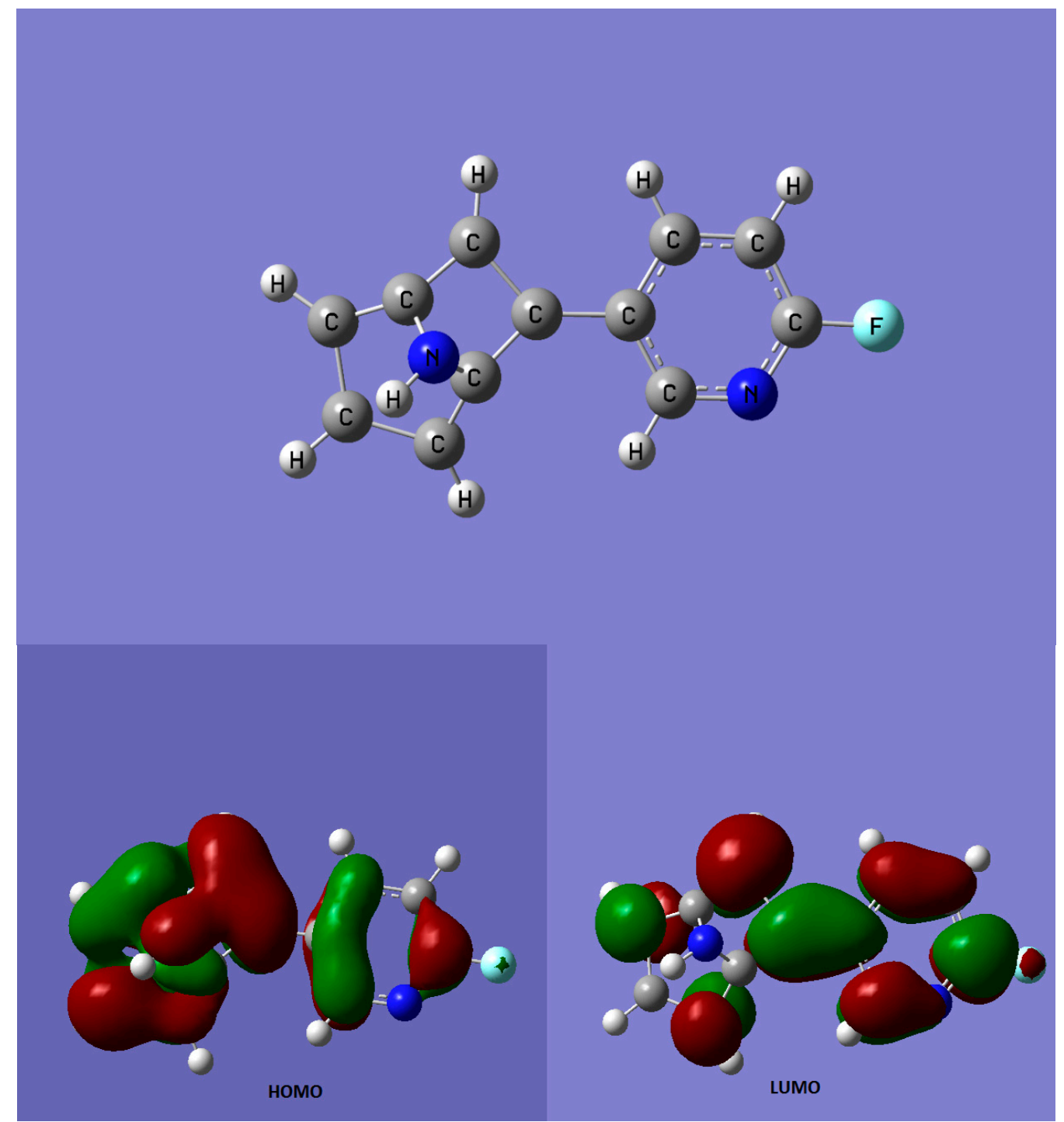

Figure 1. Chemical structure of flubatine (up) and charge distribution for the highest occupied molecular orbital (HOMO) and lowest unoccupied molecular orbital (LUMO) states (down). Methods: The ab initio calculations were performed with Gaussian 16w B.01 and modeled with GaussView 6.0.16 (Andreescu Labor Soft S.R.L., Bucharest, Romania). The optimization of the molecule and HOMO and LUMO states were calculated based on semi-empirical method PM6. It is easy to observe that the fluorine atom, for the HOMO statehas a positive charge; all the electrons are attracted on the rings. On LUMO state, the fluorine atom is partially shielded. 


\section{Role of Epibatidine in Health}

Unfortunately, the broad spectrum of epibatidine activity on a nAChRs induces several off-targets effects in several districts, such as in CNS, respiratory, gastrointestinal, and cardiovascular functions, resulting in a limited therapeutic index $(\sim 4)$, thus, precluding any therapeutic development [5]. In particular, epibatidine toxicity may be related to its ability to activate not only central neuronal $\alpha 2 \beta 2$, but also ganglionic $\alpha 3 \beta 4 \mathrm{nAchR}$. Therefore, the research community switched to modifying the epibatidine structure $[21,22]$ to obtain analogues with a better pharmacological activity/toxicity ratio and selectivity for different $\mathrm{nAchR}$ subtypes (e.g., $\alpha 2 \beta 2$ compared to $\alpha 3 \beta 4$ ) $[23,24]$.

In 1997, Badio et al. [25] synthetized ( \pm )-epiboxidine, which contains a methylisoxazolyl ring replacing the chloropyridinyl ring of epibatidine (Figure 2). The rationale behind this chemical manipulation was inspired by ABT-418 (3-Methyl-5-[(2S)-1-methyl-2-pyrrolidinyl]isoxazole hydrochloride), a nicotine analogue with a methylisoxazolyl ring instead of a pyridine one. ABT- 418 is a $\alpha 4 \beta 2$ selective full agonist, that has been used in a study for the treatment of cognitive dysfunction [26]. In that research, epiboxidine showed of about 10-fold less potency than epibatidine, but about 17-fold greater than ABT-418 in inhibiting $\left[{ }^{3} \mathrm{H}\right]$ nicotine binding to $\alpha 4 \beta 2$ nicotinic receptors on rat cerebral cortical membranes. Although the epiboxidineantinociceptive activity was about 10 -fold less potent than epibatidine, isoxazolylbioisoster showed reduced toxicity in mice [25].
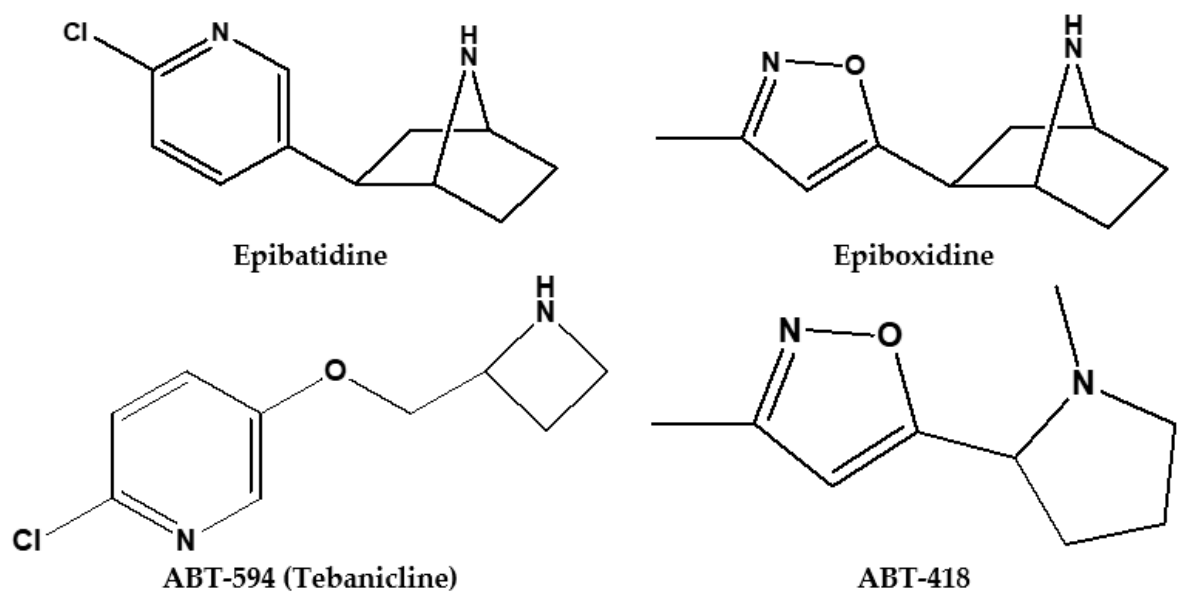

Figure 2. Epibatidine and its analogues.

Later, compound ABT-594, [(R)-5-(2-azetidinylmethoxy)-2-chloropyridine], also known as tebanicline, was synthetized by Abbott [27] and was the first-in-class compound to reach clinical trials evaluation for neuropathic pain treatment (Figure 2). Preclinical studies in animals using ABT-594 showed no adverse effects of opioids: pharmacological dependence, respiratory depression and a greater analgesic effect. It was able to selectively inhibit the afferent transmission of acute (chemical or thermal), chronic or peripheral diabetic neuropathic pain signal [28,29]. The analgesic doses of ABT-594 ranged between 0.04 and $0.12 \mathrm{mg} / \mathrm{kg}$, intraperitoneal ABT-594 administration at maximum doses produced adverse effects, such as hypothermia, hyperreactivity, and deficiency in voluntary movement control and body posture (ataxia) [30]. Preclinical evaluations in acute thermal pain (hot-plate) and persistent pain (formalin test) models indicated an efficient antinociceptive activity, predominately mediated by central neuronal $\mathrm{nAChRs}$, although a contribution of peripheral $\mathrm{nAChRs}$ is not completely excluded [31].

Over the last two decades, the concept of multimodal analgesia has emerged to treat acute or chronic pain. It consists of an administration of two analgesic drugs from different pharmacological classes, with known and different mechanism of action, at smaller doses with the consequent reduction of adverse effects. This concept was used in a study carried out by Munro et al. [32], who associated ABT-594 with gabapentin, an antiepileptic drug which interacts with high affinity with voltage-sensitive 
$\mathrm{Ca}^{2+}$ channels in the brain [33], morphine ( $\mu$-opioid receptor agonist) and duloxetine (a potent inhibitor of neuronal reuptake of serotonin and norepinephrine) in rat formalin test. In the combination with gabapentin, mecamylamine administration (a non-selective $\mathrm{nAChR}$ antagonist) at the same time as ABT-594, removes the analgesic effect. Thus, supra-spinal action site at the raphe magus nucleus was then confirmed [34]. The results obtained by authors were surprising since the pharmacologically inactive doses of ABT-549 $(0.01-0.3 \mathrm{mg} / \mathrm{kg})$ associated with lower doses of each analgesic had proven synergistic analgesic effects [32].

At the outset, ABT-594 did not show sedative-like effects on electroencephalography typically induced by opioids, but additional studies have highlighted a partial involvement of opioid receptors through indirect activation [35].

The observed side effects (decrease in body temperature and impaired motor coordination) were significantly reduced with repeated administration [31]. A phase 2, randomized, multicenter, double-blind, placebo-controlled study with ABT-594 was conducted to assess the analgesic efficacy and safety profile in patients affected by diabetic peripheral neuropathic pain [29]. In all groups of patients treated with different doses $(150,225$ and $300 \mu \mathrm{g})$, ABT-594 was able to induce a significant decrease in pain severity, in agreement with preclinical observations. Unfortunately, withdrawal rates due to adverse events were significantly higher in the three groups of ABT-594-treated patients, who presented nausea, dizziness, vomiting, abnormal dreams, and asthenia, consistent with the side effects profile of the class.

However, ABT-594 may be potentially useful as adjunctive therapy or in combination, since low doses did not activate $\alpha 3$-containing $n A C h R s$, which are related with various autonomic nervous system side effects, such as cardiovascular and gastrointestinal [36].

Additional investigations on epibatidine and its analogues have revealed a high therapeutic potential in further diseases, as well as pain. In fact, as nAChRs are functionally involved in many essential CNS cellular mechanisms, including learning, anxiety, memory, and cognitive function, several $\mathrm{nAchR}$ ligands have been developed for the treatment of many pathologies, such as AD, attention deficit hyperactivity disorder (ADHD), anxiety, Parkinson's disease, inflammatory bowel disorder, schizophrenia, depression, and many others [22]. For example, patients affected by neurodegenerative diseases, such as AD have a severe deficiency in nAChRs levels, suggesting a role for $\mathrm{nAChR}$ loss in cognitive decline in AD. This hypothesis is supported by PET studies in patients with AD, which demonstrated, on one hand, a correlation between a reduced nAChRs expression in brain and cognitive impairment grade and, on the other hand, an increase in nAChR density associated with better performance in cognitive tests after tacrine treatment [37]. Therefore, the availability of non-invasive tools for detecting the brain level of nAChRs could aid in early AD diagnosis, even at a pre-symptomatic stage, as well as in the development of personalized therapeutic regimens and in monitoring the efficacy of drug treatment [38].

Belluardo et al. [39] demonstrated that epibatidine induces fibroblast growth factor (FGF)-mRNA up-regulation, accompanied by an increase in FGF2 protein levels in rat brain, suggesting a neuroprotective effect of this natural alkaloid. In addition, epibatidine showed to be able to improve antioxidant and antiapoptotic effects, increasing heme oxygenase-1 (HO-1) expression, one of the main cytoprotective enzymes against oxidative stress [40].

Although no epibatidine derivative with neuroprotective activity has been synthetized so far, this option could represent a valid strategy to be followed. For instance, the clinical use of the nicotinic analogue ABT-418 has already been explored in moderate AD [41] and in less severe ADHD in adults [42]. The experimental in vitro and in vivo studies of epibatidine and its derivatives are summarized in Table 1. 
Table 1. Pharmacological studies of epibatidine and its synthetic derivatives.

\begin{tabular}{|c|c|c|c|}
\hline Compound & \multicolumn{2}{|c|}{ Type of Study } & \multirow{2}{*}{ References } \\
\hline \multicolumn{3}{|c|}{ In Vivo Studies Using Animal Models } & \\
\hline \multirow{5}{*}{ Epibatidine } & Animal model & Primary outcomes & \\
\hline & Mice and rats & Antinociceptive & [6] \\
\hline & Rats & $\begin{array}{l}\text { Increased adrenaline and noradrenaline } \\
\text { neuromediators }\end{array}$ & [12] \\
\hline & Pregnant goats & $\begin{array}{l}\text { Lack of completely inhibition of fetal } \\
\text { movement }\end{array}$ & [11] \\
\hline & Rats & Neuroprotective & [39] \\
\hline ABT-594 tebanicline & $\begin{array}{l}\text { Rodent pain models (rats, mice) } \\
\text { Rat formalin test }\end{array}$ & $\begin{array}{c}\text { Antinociceptive } \\
\text { Analgesic (multimodal analgesia) }\end{array}$ & $\begin{array}{c}{[27,28,30,31,35]} \\
{[32]}\end{array}$ \\
\hline Epiboxidine & $\begin{array}{l}\text { Rats } \\
\text { Mice }\end{array}$ & $\begin{array}{l}\text { Cognitive disfunction treatment } \\
\text { Antinociceptive }\end{array}$ & [26] \\
\hline \multicolumn{4}{|c|}{ In vitro studies using cell lines } \\
\hline Epibatidine & Bovine chromaffin cells & Antioxidant, antiapoptotic & [40] \\
\hline \multicolumn{4}{|c|}{ Human clinical studies } \\
\hline ABT-594tebanicline & $\begin{array}{c}\text { Study design } \\
\text { Randomized, multicenter, } \\
\text { double-blind, } \\
\text { placebo-controlled study (phase 2) }\end{array}$ & $\begin{array}{c}\text { Primary outcomes } \\
\text { Analgesic in diabetic patients with } \\
\text { neuropathic pain }\end{array}$ & [29] \\
\hline \multirow{2}{*}{ ABT-418Epiboxidine } & $\begin{array}{c}\text { Double-blind, } \\
\text { placebo-controlled study }\end{array}$ & $\begin{array}{l}\text { Cognitive enhancement in moderate } \\
\text { Alzheimer's disease }\end{array}$ & [41] \\
\hline & $\begin{array}{l}\text { Double-blind, randomized, } \\
\text { placebo-controlled, crossover trial }\end{array}$ & $\begin{array}{l}\text { Increased attention in deficit hyperactivity } \\
\text { disorder (ADHD) in adults }\end{array}$ & [42] \\
\hline
\end{tabular}

In addition to its potential therapeutic role, epibatidine also represents an important research tool to investigate nAChR activity. Notably, $\left[{ }^{3} \mathrm{H}\right]$ epibatidine binds to $\mathrm{nAchRs}$ with very high affinity and extremely low non-specific binding. This radioligand easily crosses the blood brain barrier, binds reversibly to nAChRs and exhibits a moderately fast metabolism; therefore, it has been largely used for over 20 years as radioligand to study nAChRs [14,43]. From 1995, when $\left[{ }^{3} \mathrm{H}\right]$ epibatidine was firstly described, different radiolabeled $\left({ }^{11} \mathrm{C},{ }^{18} \mathrm{~F},{ }^{76} \mathrm{Br}\right.$ and $\left.{ }^{123} \mathrm{I}\right)$ analogues were developed for in vitro and in vivo PET and single-photon emission computed tomography (SPECT) studies [37]. Recently, the exploration of the interaction of epibatidine with $\alpha 7$ receptor binding sites was carried out to lay a background for the design of specific epibatidine-based molecular probes, useful to investigate $\alpha 7$ function [8].

\section{Conclusions}

Epibatidine and its analogues have revealed a promising therapeutic potential in further diseases as well as pain. Data published show a low affinity and scarce binding of either epibatidine and its synthetic analogues to plasma proteins, indicating their availability for metabolism. However, quantitative data show that the amounts of both plasma and urinary metabolites are negligible compared to the amounts of underivatized compounds, indicating that, in general, they are not prone to metabolism. Due to severe gastrointestinal side effects, the first analogue of epibatidine, ABT-594, is not included in current pain therapies in humans. However, another new synthetic derivative of epibatidine ABT-418 is used in treatment of less severe ADHD in adult patients. ABT- 418 has been well-tolerated by patients with minor side effects, such us nausea, dizziness, headaches, or skin irritations. Thus, epibatidine pharmacological effects open new perspectives in drug therapies and also represent an important research tool to investigate $\mathrm{nAChR}$ activity.

Author Contributions: All authors contributed equally to this work. B.S., M.S.-R., S.P., N.M., and J.S.-R. critically reviewed the manuscript. All authors read and approved the final manuscript.

Funding: The APC was funded by N.M. 
Acknowledgments: Martins N. would like to thank the Portuguese Foundation for Science and Technology (FCT-Portugal) for the Strategic project reference UID/BIM/04293/2013 and "NORTE2020—Programa Operacional Regional do Norte" (NORTE-01-0145-FEDER-000012).

Conflicts of Interest: The authors declare no conflict of interest.

\section{References}

1. Spande, T.F.; Garraffo, H.M.; Yeh, H.J.; Pu, Q.L.; Pannell, L.K.; Daly, J.W. A new class of alkaloids from a dendrobatid poison frog: A structure for alkaloid 251f. J. Nat. Prod. 1992, 55, 707. [CrossRef] [PubMed]

2. Spande, T.F.; Garraffo, H.M.; Edwards, M.W.; Yeh, H.J.C.; Pannell, L.; Daly, J.W. Epibatidine: A novel (chloropyridyl)azabicycloheptane with potent analgesic activity from an Ecuadoran poison frog. J. Am. Chem. Soc. 1992, 3475. [CrossRef]

3. Posadas, I.; Lopez-Hernandez, B.; Cena, V. Nicotinic receptors in neurodegeneration. Curr. Neuropharmacol. 2013, 11, 298-314. [CrossRef] [PubMed]

4. Boyle, J. Molecular biology of the cell, by b. Alberts, a. Johnson, j. Lewis, m. Raff, k. Roberts, and p. Walter. Biochem. Mol. Biol. Educ. 2008, 36, 317-318. [CrossRef]

5. Lloyd, G.K.; Williams, M. Neuronal nicotinic acetylcholine receptors as novel drug targets. J. Pharmacol. Exp. Ther. 2000, 292, 461-467. [PubMed]

6. Qian, C.; Li, T.; Shen, T.Y.; Libertine-Garahan, L.; Eckman, J.; Biftu, T. Epibatidine is a nicotinic analgesic. Eur. J. Pharmacol. 1993, 250, 13-14. [CrossRef]

7. Sullivan, J.P.; Decker, M.W.; Brioni, J.D.; Donnelly-Roberts, D.; Anderson, D.J.; Bannon, A.W.; Kang, C.H.; Adams, P.; Piattoni-Kaplan, M.; Buckley, M.J. (+/-)-epibatidine elicits a diversity of in vitro and in vivo effects mediated by nicotinic acetylcholine receptors. J. Pharmacol. Exp. Ther. 1994, 271, 624-631. [PubMed]

8. Thompson, A.J.; Metzger, S.; Lochner, M.; Ruepp, M.-D. The binding orientation of epibatidine at $\alpha 7$ nach receptors. Neuropharmacology 2017, 116, 421-428. [CrossRef]

9. Baranowska, U.; Wiśniewska, R.J. The $\alpha 7$-nach nicotinic receptor and its role in memory and selected diseases of the central nervous system. Postepy. Hig. Med. Dosw. 2017, 30, 633-648. [CrossRef]

10. Donnelly-Roberts, D.L.; Puttfarcken, P.S.; Kuntzweiler, T.A.; Briggs, C.A.; Anderson, D.J.; Campbell, J.E.; Piattoni-Kaplan, M.; McKenna, D.G.; Wasicak, J.T.; Holladay, M.W.; et al. Abt-594 [(r)-5-(2-azetidinylmethoxy)-2-chloropyridine]: A novel, orally effective analgesic acting via neuronal nicotinic acetylcholine receptors: I. In vitro characterization. J. Pharmacol. Exp. Ther. 1998, 285, 777-786.

11. Shimizu, T.; Tanaka, K.; Hasegawa, T.; Yokotani, K. Brain $\alpha 4 \beta 2$ nicotinic acetylcholine receptors are involved in the secretion of noradrenaline and adrenaline from adrenal medulla in rats. Eur. J. Pharmacol. 2011, 654, 241-248. [CrossRef] [PubMed]

12. Green, B.T.; Lee, S.T.; Keele, J.W.; Welch, K.D.; Cook, D.; Pfister, J.A.; Kem, W.R. Complete inhibition of fetal movement in the day 40 pregnant goat model by the piperidine alkaloid anabasine but not related alkaloids. Toxicon 2018, 144, 61-67. [CrossRef] [PubMed]

13. Traynor, J.R. Epibatidine and pain. Br. J. Anaesth. 1998, 81, 69-76. [CrossRef] [PubMed]

14. London, E.D.; Scheffel, U.; Kimes, A.S.; Kellar, K.J. In vivo labeling of nicotinic acetylcholine receptors in brain with [3h] epibatidine. Eur. J. Pharmacol. 1995, 278, R1-R2. [CrossRef]

15. Javors, M.A.; Sanchez, J.J.; King, T.S.; Rohde, A.R.; Wilson, S.G.; Flores, C.M. Extraction and quantification of epibatidine in plasma. J. Chromatogr. B Biomed. Sci. Appl. 2001, 755, 379-382. [CrossRef]

16. Shiraishi, Y.; Ogawa, T.; Suzuki, T. Simultaneous quantification of batrachotoxin and epibatidine in plasma by ultra-performance liquid chromatography/tandem mass spectrometry. Legal. Med. 2017, 25, 1-5. [CrossRef] [PubMed]

17. Watt, A.P.; Hitzel, L.; Morrison, D.; Locker, K.L. Determination of the in vitro metabolism of (+)- and (-)-epibatidine. J. Chromatogr. A 2000, 896, 229-238. [CrossRef]

18. Heugebaert, T.S.A.; Van Overtveldt, M.; De Blieck, A. Synthesis of 1-substituted epibatidine analogues and their in vitro and in vivo evaluation as a4ß32 nicotinic acetylcholine receptor ligands. RSC Adv. 2014, 4, 2226-2234. [CrossRef]

19. Patt, M.; Becker, G.A.; Grossmann, U. Evaluation of metabolism, plasma protein binding and other biological parameters after administration of $(-)-\left[{ }^{18} \mathrm{f}\right]$ flubatine in humans. Nucl. Med. Biol. 2014, 41, 489-494. [CrossRef] 
20. Ludwig, F.; Fischer, S.; Smits, R. Exploring the metabolism of (+)-[18f] flubatine in vitro and in vivo: Lc-ms/ms aided identification of radiometabolites in a clinical pet study. Molecules 2018, 23, 464. [CrossRef]

21. Bunnelle, W.H.; MJ Dart, M.; Schrimpf, M.R. Design of ligands for the nicotinic acetylcholine receptors: The quest for selectivity. Curr. Top. Med. Chem. 2004, 4, 299-334. [CrossRef] [PubMed]

22. Yogeeswari, P.; Sriram, D.; Bal, T.R.; Thirumurugan, R. Epibatidine and its analogues as nicotinic acetylcholine receptor agonist: An update. Nat. Prod. Res. 2006, 20, 497-505. [CrossRef] [PubMed]

23. Carroll, F.I. Epibatidine structure-activity relationships. Bioorganic Med. Chem. Lett. 2004, 14, 5713.

24. Seerden, J.G.; Tulp, M.T.; Scheeren, H.W.; Kruse, C.G. Synthesis and structure-activity data of some new epibatidine analogues. Bioorganic Med. Chem. Lett. 1998, 6, 2103-2110. [CrossRef]

25. Badio, B.; Garraffo, H.M.; Plummer, C.V.; Padgett, W.L.; Daly, J.W. Synthesis and nicotinic activity of epiboxidine: An isoxazole analogue of epibatidine. Eur. J. Pharmacol. 1997, 321, 189-194. [CrossRef]

26. Rizzi, L.; Dallanoce, C.; Matera, C.; Magrone, P.; Pucci, L.; Gotti, C.; Clementi, F.; De Amici, M. Epiboxidine and novel-related analogues: A convenient synthetic approach and estimation of their affinity at neuronal nicotinic acetylcholine receptor subtypes. Bioorg. Med. Chem. Lett. 2008, 18, 4651-4654. [CrossRef] [PubMed]

27. Holladay, M.W.; Wasicak, J.T.; Lin, N.-H.; He, Y.; Ryther, K.B.; Bannon, A.W.; Buckley, M.J.; Kim, D.J.; Decker, M.W.; Anderson, D.J. Identification and initial structure-Activity relationships of (r)-5-(2-azetidinylmethoxy)-2-chloropyridine (abt-594), a potent, orally active, non-opiate analgesic agent acting via neuronal nicotinic acetylcholine receptors. J. Med. Chem. 1998, 41, 407-412. [CrossRef]

28. Meyer, M.D.; Anderson, D.J.; Campbell, J.E.; Carroll, S.; Marsh, K.C.; Rodrigues, A.D.; Decker, M.W. Preclinical pharmacology of abt-594: A nicotinic acetylcholine receptor agonist for the treatment of pain. CNS Drug Rev. 2000, 6, 183-194. [CrossRef]

29. Rowbotham, M.C.; Duan, W.R.; Thomas, J.; Nothaft, W.; Backonja, M.-M. A randomized, double-blind, placebo-controlled trial evaluating the efficacy and safety of abt-594 in patients with diabetic peripheral neuropathic pain. Pain 2009, 146, 245-252. [CrossRef]

30. Boyce, S.; Webb, J.K.; Shepheard, S.L.; Russell, M.G.; Hill, R.G.; Rupniak, N.M. Analgesic and toxic effects of abt-594 resemble epibatidine and nicotine in rats. Pain 2000, 85, 443-450. [CrossRef]

31. Bannon, A.W.; Decker, M.W.; Curzon, P.; Buckley, M.J.; Kim, D.J.; Radek, R.J.; Lynch, J.K.; Wasicak, J.T.; Lin, N.-H.; Arnold, W.H. Abt-594 [(r)-5-(2-azetidinylmethoxy)-2-chloropyridine]: A novel, orally effective antinociceptive agent acting vianeuronal nicotinic acetylcholine receptors: Ii. In vivocharacterization. J. Pharmacol. Exp. Ther. 1998, 285, 787-794. [PubMed]

32. Munro, G.; Dyhr, H.; Grunnet, M. Selective potentiation of gabapentin-mediated antinociception in the rat formalin test by the nicotinic acetylcholine receptor agonist abt-594. Neuropharmacology 2010, 59, 208-217. [CrossRef] [PubMed]

33. Taylor, C.P. Mechanisms of action of gabapentin. Rev. Neurol. 1997, 153 (Suppl. 1), S39-S45. [PubMed]

34. Bitner, R.S.; Nikkel, A.L.; Curzon, P.; Arneric, S.P.; Bannon, A.W.; Decker, M.W. Role of the nucleus raphe magnus in antinociception produced by abt-594: Immediate early gene responses possibly linked to neuronal nicotinic acetylcholine receptors on serotonergic neurons. J. Neurosci. 1998, 18, 5426-5432. [CrossRef] [PubMed]

35. Hayashi, T.; Katsuyama, S.; Orito, T.; Suzuki, T.; Sakurada, S. Antinociceptive effect of tebanicline for various noxious stimuli-induced behaviours in mice. Neurosci. Lett. 2017, 638, 46-50. [CrossRef] [PubMed]

36. Hone, A.J.; McIntosh, J.M. Nicotinic acetylcholine receptors in neuropathic and inflammatory pain. FEBS Lett. 2018, 592, 1045-1062. [CrossRef] [PubMed]

37. Sihver, W.; Nordberg, A.; Långström, B.; Mukhin, A.G.; Koren, A.O.; Kimes, A.S.; London, E.D. Development of ligands for in vivo imaging of cerebral nicotinic receptors. Behav. Brain Res. 2000, 113, 143-157. [CrossRef]

38. Sihver, W.; Långström, B.; Nordberg, A. Ligands for in vivo imaging of nicotinic receptor subtypes in alzheimer brain. Acta Neurol. Scand. 2000, 102, 27-33. [CrossRef]

39. Belluardo, N.; Mudò, G.; Blum, M.; Cheng, Q.; Caniglia, G.; Dell'Albani, P.; Fuxe, K. The nicotinic acetylcholine receptor agonist $( \pm$ )-epibatidine increases fgf-2 mrna and protein levels in the rat brain. Mol. Brain Res. 1999, 74, 98-110. [CrossRef]

40. Egea, J.; Rosa, A.O.; Cuadrado, A.; García, A.G.; López, M.G. Nicotinic receptor activation by epibatidine induces heme oxygenase- 1 and protects chromaffin cells against oxidative stress. J. Neurochem. 2007, 102, 1842-1852. [CrossRef] 
41. Potter, A.; Corwin, J.; Lang, J.; Piasecki, M.; Lenox, R.; Newhouse, P.A. Acute effects of the selective cholinergic channel activator (nicotinic agonist) abt-418 in alzheimer's disease. Psychopharmacology 1999, 142, 334-342. [CrossRef] [PubMed]

42. Wilens, T.E.; Biederman, J.; Spencer, T.J.; Bostic, J.; Prince, J.; Monuteaux, M.C.; Soriano, J.; Fine, C.; Abrams, A.; Rater, M. A pilot controlled clinical trial of abt-418, a cholinergic agonist, in the treatment of adults with attention deficit hyperactivity disorder. Am. J. Psychiatry 1999, 156, 1931-1937. [PubMed]

43. Perry, D.C.; Kellar, K.J. [3h] epibatidine labels nicotinic receptors in rat brain: An autoradiographic study. J. Pharmacol. Exp. Ther. 1995, 275, 1030-1034. [PubMed]

2018 by the authors. Licensee MDPI, Basel, Switzerland. This article is an open access article distributed under the terms and conditions of the Creative Commons Attribution (CC BY) license (http://creativecommons.org/licenses/by/4.0/). 